\title{
\begin{tabular}{l|l} 
Peter Wilkins & The Pantheon as a Globe-Shaped Conception
\end{tabular} Conference Report \\ The Pantheon: "Symbol of the universe" and "The Interpretation in Northern Europe"
}

Pantheon, Rome, in the rooms of the Accademia di San Luca

23 September 2001 and 21 March 2002

\section{The Principles of Reflection}

Over the past years research about the Pantheon has greatly developed, especially after the publication of the new survey by Pelletti. ${ }^{1}$ This has highlighted the fact that the reasons behind the design and the function of the building are still not absolutely clear. ${ }^{2}$ During the autumn 2001 and the spring 2002 equinoxes, Giangiacomo Martines, director of the Soprintendenza di Archeologia di Roma, participated in the observation of the Pantheon, along with its ancillary rooms and base of the dome, giving rise to several new perspectives and views. It was possible to verify hypothetical assumptions through direct observation of the building itself, and to formulate the yet unanswered questions of research. In his classic work on the Pantheon, Kjeld de Fine Licht ${ }^{3}$ had already described the difficult conditions for research, since the Rotunda, because as one of the most important Roman churches with its own traditional observations of feast days, it offers only restricted access for research work. As noted by Friedrich Rakob of the German Archaeological Institute in Rome, even today the Pantheon poses a whole complex of significant unsolved questions.

A comparison of proportions between the Roman Pantheon and the "Pantheon of Books" in Wolfenbüttel clearly shows a similarity between the canons of form of meaningful elements: circle/ellipse; pavement design; the spherical cupola. These are displayed in an attractive collage by Lambert Rosenbusch.

By chance discovery in the southern bay of the Pantheon, in a room supported by a multistorey structure of massive supports and buttresses, the participants encountered a variety of associative and interrelated clues. In the solid rear wall of the shell of the dome can be observed certain cracks caused by circular tension forces during construction. But, as Gert Sperling hypothesized, there is also a clearly visible rectangular slit in the dome, now bricked in, on the southern meridian, to-gether with the remains of a staircase, the steps of which were apparently removed at a later time. Since from this position it is possible to observe directly the Himmelspol, the zenith of the sky, through the middle of the oculus, based on the latitude of Rome, it is therefore logical to pose the question, Did the library erected by Julius Africanus in about 240 A.D. have a simple observatory, a room for the direct observation of the sky? This would be a further point of similarity on the theme of "The Pantheon of books" in Wolfenbüttel, Leibniz's famous library (Fig. 1).

Considering the design of libraries based on generally understood scientific facts at that time, observation of the sky would have been one of the main activities. It could therefore be concluded that the Italien Fahrer, traveller to Italy, from Wolfenbüttel also had knowledge of these facilities in the Pantheon. 


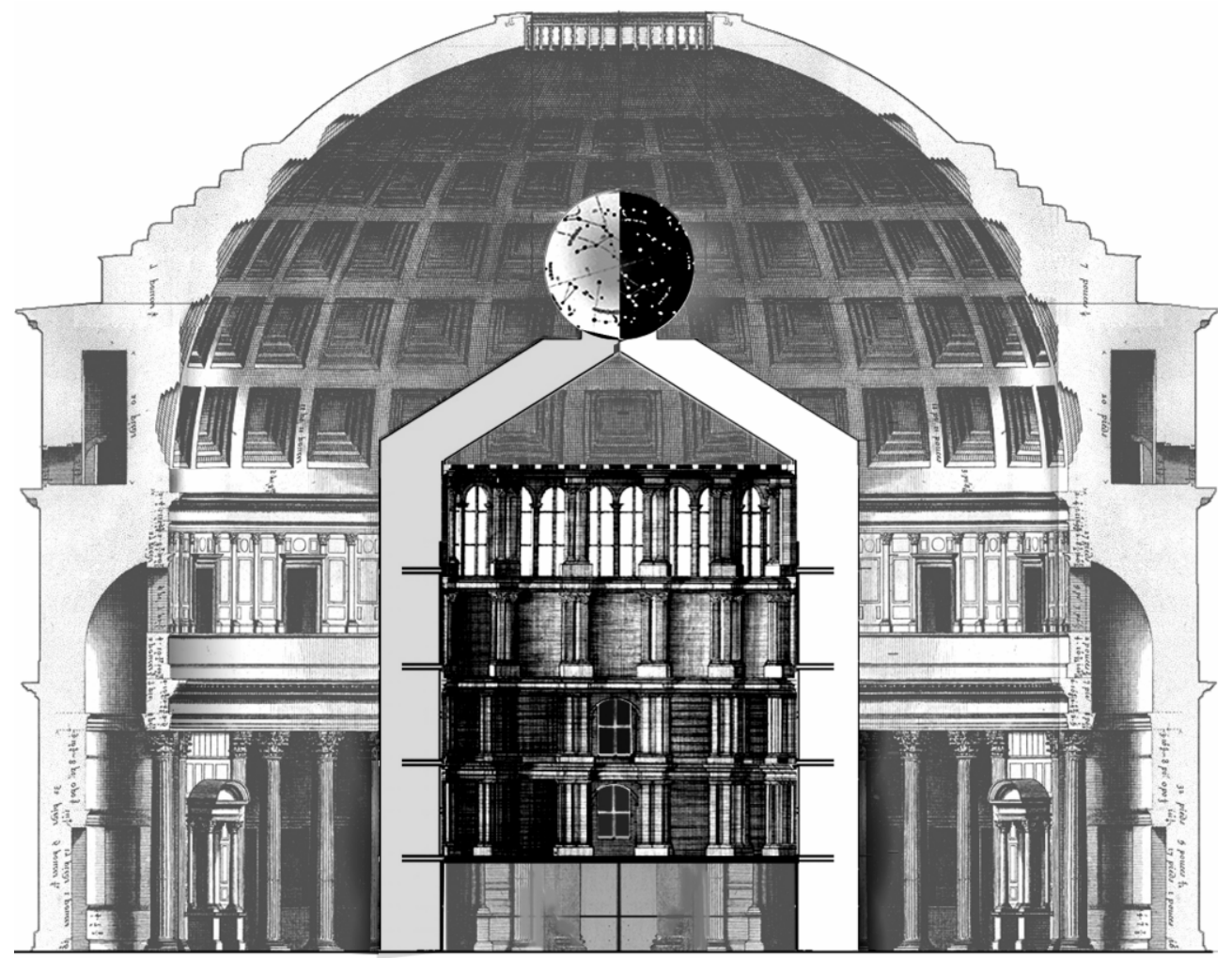

Fig. 1. A section of the library at Wolfenbüttel superimposed on the section of the Pantheon, Rome. Section of the Wolfenbüttel library by Hamburg architects WilkensRosenbusch; section of the Pantheon by Desgodetz. Formal and style similarities are clearly noticeable. This is particularly true of the design of the wall surfaces of the upper floors of the Wolfenbüttel building compared to the existing zones of the Pantheon.

Such knowledge might have been collected from discussions similar to those held at our own March 2001 meeting, or from knowledge gleaned from the archives. Thus the north European interpretation in this building during the Enlightenment had more significant links to the ancient dome, beyond those of pure architectural imitation. The reference to the Pantheon theme in rotunda-like constructions is not particularly unusual, as shown by numerous historical copies. ${ }^{4}$ However, in Wolfenbüttel we are concerned with the recreation of the prototype of a revolutionary form, the oval cylinder linking both the spirit of classicism and the cosmos of a library. The form of the "cosmic image" is combined in symbolic unity with the Alexandrian library in the Pantheon. The ancient Pantheon is equally entitled to the title "Pantheon of Books", thus Paul Raabe would call Wolfenbüttel the "eighth Wonder of the World," and F. Matthisson would describes the cosmos of books as "Pantheon." Both these verbal depictions describe effectively the exceptional esteem enjoyed by this classical interpretation north of the Alps. The unusual elliptical shape of the internal space of the Wolfenbüttel cylinder distinguishes it from the usual replicas of the Pantheon. The adaptation of shapes, constructional system and design function to create a new symbiosis represents not a simple revision of the original, but a further step in intellectual development. Leibniz, the splendid spirit of his inventive age, and his 
architect Korb, down-to-earth but Italian influenced, followed their noble patron's request that they bear costs in mind. Das Bauwesen rutschet vortrefflich, feget aber den Beuthel, "the design is perfect, if it reduces the budget", was a comment coined by Friedrich Karl von Schönborn. ${ }^{5}$ The ideals and conceptions of antiquity were translated beyond the Alps to a northern European situation, and founded, as it were, on the shoulders of the ancient, the rediscovered aesthetic adequately suited the new humanistic way of thinking.

A comparison of detail illustrates the general relationships. The original decoration of the attic of the Roman rotunda, redecorated in 1747 with the introduction of neo-classic elements and which today has been restored for visitors in a south-western segment, features a geometric marble construction of seven colours. Its mathematical refinement is due to the fact that the height and width of the decorative panels are not merely proportional to each other, but are governed by a whole series of numerical relationships based on their diagonal measurements. ${ }^{6}$ The aedicula and pilasters of the lower stories are repeated above at a smaller scale, their division into thirty-two stressing the tension between cylinder and dome, which itself is formed out of twenty-eight rows of coffers. According to the ancients, harmony occurs when formal and numeric opposites are woven together, fused; ${ }^{7}$ in this case, even and odd, 7 and 8 , and circle and square, are combined in the design of each trapezoid-shaped coffer. The astronomical meaning should not be overlooked, as the coffers serve to illustrate astronomical time cycles though whole numbers. According to the Julian calendar, the first Sunday after the first full moon after the first day of spring falls again on the same date exactly 532 years later. The dome of the Pantheon contains exactly 532 coffers (28 segments times 19 stages of coffers $=532) .{ }^{8}$

The architectural elements of the Leibniz rotunda, with its aediculae, pilasters, and columns, were similar. The penetration of light was controlled by the windows surrounding the cone of the cylinder. The high lateral lighting with its soft reflections was in contrast to the Pantheon, where the vertical illumination appears hard. In spite of the difference in the light sources, their effect on the spectator entering the space would have been similar, as the light source is eclipsed by the height of the room and it is not immediately apparent to the eye.

The Pantheon as a Gesamtraum, architectural whole, is not "illuminated" by the oculus. There is no creation of the luminous effects of later constructions, such as that of the lumen spiritualis of the Hagia Sophia. The light from the oculus is focused as a beam, becoming an object and an instrument, most effective in strong sunlight. However, during our spring 2002 meeting the concentrated ray of moonlight merited particular attention. In order to observe the moon when it was in a high position, the participants of the meeting were allowed to remain in the unlighted space after it has been closed to the public. On this particular evening both the moon and Jupiter were visible in the oculus, a unique constellation (Fig. 2).

The observations made apparent the basic concept of the spatial design. The gentle moonlight blurred the decorative details and emphasized the structural elements of the rotunda. The globeshaped concept crystallized into the echoing harmony of the sphere-shaped room. Even the weak rays of the half-moon lent the space a mysterious atmosphere, in which the distance in time from the first to the twenty-first century physically was made almost tangible. 


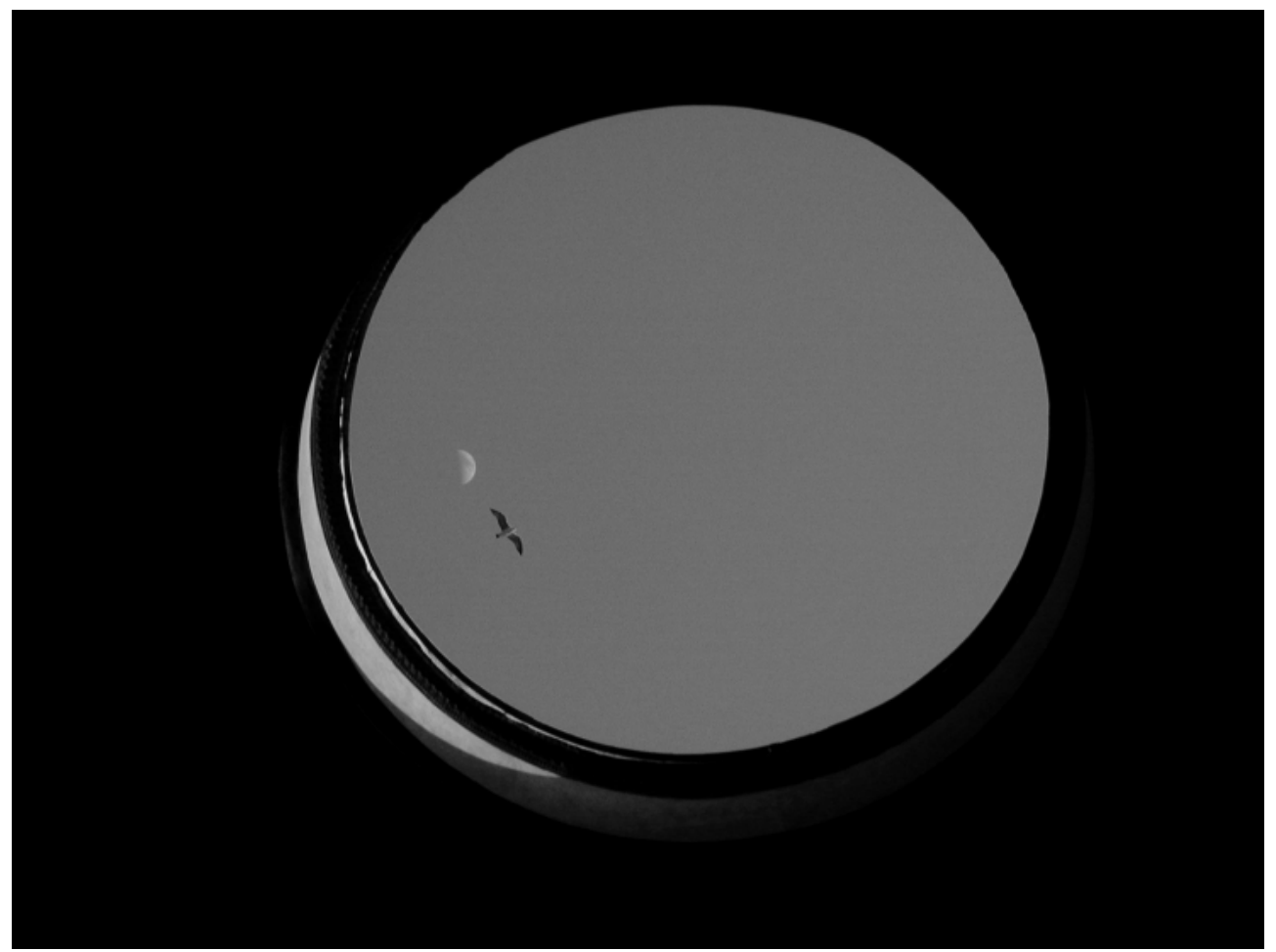

Fig. 2. The Pantheon, Rome, with the moon and Jupiter. Using electronic enhancement a picture of the night sky was created on 21 March 2002. The moonlight creates a clearly visible circular reflection of cool light on the floor of the Pantheon. The crescent of the moon stood in the deep light blue evening sky together with brightly shining Jupiter opposite in the oculus.

\section{Concerning Reflection}

The moon acts as a reflector, changing sunlight into a reflected moonlight, which is the light that strikes the earth. This reflected light is in its turn reflected by the earth- "moonshine" to "earthshine" - and is visible on the dark surface of the moon during the night's ascending first quarter. In principle, an infinite flectio / reflectio takes place. In theory this is similar to sound waves, so that we call it a "light echo."

For both light and sound, the ideal conditions occur at night. During the day the primary energy sources coming from the sun and from high level of ambient noise disturbs this field, so that they only can dominate during night-time conditions. The night phase appears phenomenologically congruent, whilst the day time phase is incongruent. The day time phase is also falsified by artificial lighting. As an instrument, the sunbeam is relatively weak in terms of its ability to give spatial form. The congruity of spatial experience involving the lux naturalis for day (sunlight) and the night (moonlight) becomes particularly important in the four-band echomodulation of light and sound as audio-visual phenomena, and form and colour of materials as reflective surfaces. 
Gert Sperling warns that the differences in effect that exist in the present day would not have been so accentuated in antiquity, because at that time, in the place of the lively Piazza della Rotunda (raised in level by many meters), there would have been the stoa, a quite long building, reaching out over one hundred metres to the north of the connecting forecourt. The stoa could only be entered from the northern gate, being enclosed on its sides by covered, columned, halls. This ensemble created, however, an ambient peace and stillness. If ritual ceremonies or similar activities had ever taken place in the Rotunda (of which there is no evidence), then through a planned sequence of events (liturgia), a congruency of note, sound, space, and time (through the movement of the light segments) would have been created, which would have had an intense effect on the participants.

The effect is mirrored in the multitude of reflections of moonlight. The high full moon (one) sends its image as a picture (two), which strikes the floor (three), lights the areas of the walls (four), spreads over the conchae (five), lights the columns (six), and the background (seven). After seven we are unable to sense anything further, and we terminate this endless physical state at the symbolic seventh number, already established in the number of coffers of the dome $(4 \times 7=28)$. From the Apocalypse comes a symbolic image for the 7: the trumpet's seven blasts destroyed and rebuilt (!) the Walls of Jericho.

By this echoed lighting, the space was "illuminated," that is, through the physical reflection in the four echo zones the space almost reconstructs itself. This causes reflectio humana in the psyche and intellect of the spectator. Thus the struttura umana is formed here by a three fold overlay, which increases in monumentality during the experience of the space at night. ${ }^{9}$

\section{Concerning Sky Observations}

The movement of the rays of sunlight and their reflections on the floor, cylinder walls and dome segments are manifestations of the daily rotation of the earth, and the movement of earth around the sun along its sloping ecliptic plane. The rotation of the lux naturalis demonstrates the sequence of movement of the planet earth, thus this representation is heliocentric and Copernican. In accordance with ancient gnomon theory, the point of the gnomon of a sundial, which creates the shadow, represented the stationary earth, while the movement of the shadow represented the movement of the sun around the earth. However, in the oculus of the Pantheon the sun is displayed as the fixed source of light. The centre of the oculus symbolizes the stationary point of the gnomon, and the movement of the rays of light indicates the rotation of the earth on its axis and the movement on its eclipse. Thus in the Pantheon, the ancient heliocentric theory is already present. Giordano Bruno would have recognised this, as he completed his studies nearby with the Dominicans in S. Maria sopra Minerva.

Later, in the Baroque period, the heliocentric theory was officially recognised and, as a consequence, room was sought where it would be easily possible to represent the empirically defined equinoxes and the position of the polar star to the true zenith as a basis for defining the date of Easter over a long period of time. The level floor of S. Maria degli Angeli (rebuilt by Michelangelo as a church from the former thermal baths of the Diocletian) - verifiable even today by control markings-was used by Francesco Bianchini in 1702 to layout the heliocentric meridian line and a time system with sixteen ellipses representing the movement of the polar star around the zenith. At the same time were created an opening to let in light on the north-south meridian on the southern side of the apse of the baths at a height of $20.32 \mathrm{~m}$ and a sighting canal for the polar star on the northern side of the apse at height of $24.39 \mathrm{~m} .{ }^{10}$ This was at almost the same position as in the Pantheon (oculus to dome base $=22.039=7 \mathrm{x} \mathrm{p} \mathrm{m}$ ). Lenses were mounted

82 PETER WILKINS - The Pantheon as a Globe-Shaped Conception 
on both sides of the opening-inside and outside - to help the observation and focusing of the light rays of the polar star. A diopter was also used to fix the axes of the star on the surface of the pavement. ${ }^{11}$ It was thus possible to measure the distance of the polar star to the zenith for a longer period to establish the start of spring on the ecliptic path, necessary for calculating the date of Easter over a long period. This opening for the observation of the polar star was unfortunately closed during the later restoration by Vanvitelli.

This polar star diagram is not much larger in area than 1-2 square meters, so that the space in the bricked up southern segment of the dome base in the Pantheon would be large enough. It would be sufficient to provide the oculus with cross hairs together with the additional aid of the diopter in order to create tools to observe the pole that are identical to those in S. Maria degli Angeli, as this plane follows the latitude of Rome. At that time the task was not to track the polar star but rather Taurus, with the lower Pleiades, the $\ddot{A} h r e$, the Schwanzquaste of the zodiac sign Taurus near the pole and thus also the fact that they moved and disappeared below the horizon to allow a new age to appear at ground level at Aries. The change from Taurus to Aries is formed by the backwards movement along the ecliptic path of the start of spring in relationship to the fixed position of the stars in the universe. It must have been rewarding to investigate these conditions in the former Alexandrian library of the Pantheon.

In the Wolfenbüttel rotunda the heliocentric and geocentric theories of the cosmos were interwoven. In the upper half of the cupola in Wolfenbüttel (roughly 7.8 meters in diameter) were depicted the zodiac signs of modern astrology from the eighteenth century, namely, the heliocentric Weltbild of Copernicus. Below in the lower part of the rotunda, the mythological painting placed helios, the sun, alongside the planets while gaia, the earth, was a central star, a reminiscent of the geocentric theory of the cosmos.

The intellectual product that derived from this ambiguity resulted in a spatial system somewhat like "advanced antiquity," based on a durable fixed point, lasting even to the present day. Ambiguity dominated in the globe of the eighteenth century; demolition in the nineteenth century neutralised it; the impulse of reconstruction of the twentieth century convincingly reignited the theme. Already in the Pantheon this tension can be verified and should researched in more depth.

"If all planets were to return to their original positions, the cosmos would, in principle, be as it once was. Time is also cyclical, as in the astronomic system. Time must return again if, according to the number of advancements of time, it really desires to be an image of eternity." 12 Should one wish to examine empirically the cyclic theories of Pythagoras and Plato, an architectural observation instrument such as this would be needed. Without the magnifying glass and mirror telescope, ancient architecture as a mathematical instrument is still the acme.

\section{Acknowledgment}

This report is the product of joint research with Gert Sperling. I am very grateful for his correction of my text with his profound knowledge and precise long-standing experience of Roman life. Further thanks goes to Lambert Rosenbusch, whose basic research using coordinate system photography has led to a completely revolutionized graphic interpretation. 


\section{Editor's Note}

First published in German with an English translation in the Werkbund Nord, 2002-2, and republished in the Nexus Network Journal by permission. Revised English translation by Kim Williams. Original title: "Das Pantheon als Raum-Gestalt. Erläuterung zur Reflexion”.

\section{Notes}

1. G.Gruben (Starnberg) and L. Haselberger (Philadelphia) agree that the analysis by Giangiacomo Martines and the survey by Marco Pelletti form the basis from which any other further interpretations should made. See Giangiacomo Martines, "Argomenti di geometria antica a proposito della cupola del Pantheon," Quaderni dell' Istituto di Storie dell' Architettura, no. 13, 1989, p.3ff; Marco Pelletti, "Note al rilievo del Pantheon," in Quaderni dell' Istituto di Storie dell' Architettura 13 (1989): $10 \mathrm{ff}$.

2. An summary of these unanswered questions is given by Gert Sperling in Das Pantheon in Rom: Abbild und Maß des Kosmos (ars una Verlage, 1999), 1-5.

3. Kjeld de Fine Licht, The Rotunda in Rome, Copenhagen, 1968.

4. A good summary is given in E. Heinle and J. Schleich, Kuppeln aller Zeiten-aller Kulturen, Stuttgart,1996.

5. $\quad$ Quoted by Mannfred Sack, "Bauherrenkultur," lecture at the BDA Hamburg, 1999.

6. Cf. G. Sperling, Das Pantheon in Rom: Abbild und Maß des Kosmos, $259 \mathrm{ff}$; using Ö2 it can only be approximate.

7. Karsten Harries of Yale University calls this phenomena "the coincidence of opposing extremities". An exhibit at MIT in 1999 by the same name featured John Clagett's architectural photography of Baroque churches in Central Europe. See The Coincidence of Opposing Extremities (New York: The Center for Ecumenical Research in Arts and Sciences, 1999), $8 \mathrm{ff}$.

8. Cf. H. Lichtenberg, et al. The structure of the Gregorian Calendar based on a generalisation of the Gaußian Easter Formula is presented in "Die Struktur des Gregorianischen Kalenders anhand der Verallgemeinerung der Gaußschen Osterformel dargestellt", in Sterne und Weltall, Zeitschrift für Astronomie des Max-Planck-Institutes 37, 4: 328 ff; also see Gert Sperling, Das Pantheon in Rom: Abbild und Maß des Kosmos, pp. $233 \mathrm{ff}$ for the presentation of cycles in the Pantheon.

9. $\quad$ Goethe noted in his Italienische Reise, 2 February 1787: "Nobody who has not taken one can imagine the beauty of a walk through Rome by full moon. All details are swallowed up by the huge masses of light and shadow, and only just the biggest and most general outlines are visible....This is the kind of illumination by which to see the Pantheon, the Capitol, the square in front of St. Peter's, and many other large squares and streets. Like the human spirit, thus sun and the moon have quite a different task to perform here, for here their glance is returned by gigantic, solid masses." See Italian Journey, W.H. Auden and Elizabeth Mayer, trans. London: Penguin Books, 1970, p. 168.

10. A. Schiavo, La Meridiana di S. Maria degli Angeli (Rome: 1993), 67.

11. Ibid., $99 \mathrm{ff}$.

12. Cf. von Weizsäcker, quoted in Lichtenberg, Der Garten des Menschlichen - Beiträge zur geschichtlichen Anthropologie (Munich / Vienna 1972), 341. 